\title{
Editorial
}

\section{Personal selling and sales management in the marketing of financial services: Introduction to the special issue}

Journal of Financial Services Marketing (2014) 19, 71-73. doi:10.1057/fsm.2014.12

'Nothing happens until someone sells something'. There is much bewilderment as to who originally coined this phrase. It has variously been attributed to the father of mass production, Henry Ford; Arthur 'Red' Motley, the publisher of Parade magazine; IBM chairman and CEO Thomas J. Watson, who is credited with turning the giant multinational into one of the most successful selling organizations of all time; and management guru Peter Drucker. While there may be confusion as to the origins of the expression, however, there is little doubt that even in this age of the Internet, social media and other forms of electronic marketing, personal selling is still a major tool used by firms in the financial services industry worldwide. In many domains of the financial services industry, it does seem that nothing happens until someone sells something.

The offerings of financial services firms such as banks, investment management firms, shortterm and life insurance companies still rely extensively on personal selling to explain their offerings, close deals and build relationships with customers. Financial services marketers spend enormous amounts each year on recruiting, training, organizing, communicating with and motivating their sales forces.

Successful financial services salespersons, who are good at prospecting for clients, pitching, handling objections, closing sales and implementing the follow-up that cements relationships, are often among the world's top earners, based on a combination of high salary and commission-based bonuses. Surprisingly, despite the massive investment in sales forces by financial services firms, and notwithstanding the persistent importance of personal selling in the marketing mix of financial service offerings, marketing and sales management scholars have paid meager attention in scholarly journals to both the act of selling financial services, and to the management of the sales force in the financial services firm.

This special issue solicited marketing and sales management scholars to submit papers on a wide range of topics related to the selling of financial services, and to the management of the financial services sales force. The special issue features a broad range of topics, and the papers utilize a wide variety of research approaches. The papers all focus on the management of the sales force, with special attention given to the identification of effective sales traits and the recruitment of good salespeople. A major, and unexpected drawback was a complete absence of submissions devoted to the selling of financial services, as opposed to the management of those who sell them. This certainly highlights an opportunity for this journal to publish a special issue in the future on the selling of financial services!

The papers in this special issue highlight a number of issues for marketers of financial services, including the importance of a customer-centric sales culture, of organizational 
commitment and of employer branding. In addition, the papers in this special issue explore how personality traits of employees impact firms and employee performance. Many of these papers consider the context of a rapidly changing technological landscape.

Crittenden, Crittenden, and Crittenden argue that financial service firms must adopt more technological methods, including the integration of social media with person-toperson direct selling. These authors suggest that an integrative and customer-oriented sales culture will be a key to establishing client trust and in sustaining client relationships - and thus in sustaining a competitive advantage.

The importance of a customer-oriented sales culture is further argued by Robson, Beninger and Hall, who present a longitudinal content analysis of job postings for sales and marketing professionals in financial services in both the United States and United Kingdom. They reveal that in the years since the financial crisis, the themes of client and relationships, rather than products or services, are becoming more evident in job postings perhaps indicating that in the wake of the financial crisis, financial services firms are attempting to attract employees who will assume a client or relationship-centric approach to their work. Recruitment is also a focus of the paper by Humphrey, in which the author uses data from CVs to assess whether applications for jobs in financial services are describing their experience and qualifications using the right words.

$\mathrm{Oh}, \mathrm{Rutherford}$ and Park investigate an important but overlooked link between job performance and job satisfaction of employees in the financial services industry. Ultimately, the authors suggest that there is a positive link between these two constructs, and that these also have a positive impact on organizational commitment. They highlight how workfamily conflict can also impact role conflict in the workplace, which has important implications for research and for firms. Vella, Pitt and Caruana also investigate the organizational commitment construct, and provide further support for the notions of a 'cycle of success' and a 'cycle of failure' in the workplace. Specifically, they suggest that equity sensitivity and emotional labor impact organizational commitment, and that the organizational commitment construct is important in terms of ultimate corporate performance.

Näppä, Farshid and Foster present a framework for understanding employer branding. In their paper, the authors argue that the corporate brand is highly connected to those individuals who personify the company to the customers. Further, they argue that employer branding, internal branding and corporate branding work together to communicate the core values of a financial services organization.

The final two papers explore personality traits of financial service salespersons. Lilford, Vigar-Ellis and Nel attempt to describe the characteristics of the ideal salesperson by looking at the impact of personality on their performance. The Big Five personality traits of salespeople in large financial services organizations were investigated. An important and interesting aspect of the paper is the use of Chernoff faces to simultaneously portray multivariate data in a readily comprehensible manner. The results depict salespersons' personality traits and relative performance using simple but powerful graphic devices.

Finally, Lilford also explores the Big Five personality traits, with specific emphasis on how these personality traits are links to employee resistance to change. In a world where technology is changing rapidly, the findings from this paper have important implications for firm performance.

The papers in this special issue of the Journal of Financial Services Marketing give financial services practitioners and academics much to consider as managers and researchers as they try to understand the past and build on a future in a rapidly changing marketing environment. I trust that the papers in this special issue will provide the incentive for further work on, and study of, personal selling and sales management in the financial services arena by raising new 
questions and highlighting new conceptual issues to explore. I certainly hope it also emphasizes the lacuna we currently face with regard to the activity of selling.

The special issue editor would like to thank the following reviewers:

Russell Abratt, Nova Southeastern University

Anjali Bal, Babson College

Stefanie Beninger, Simon Fraser

University

Elsamari Botha, University of Cape Town

Pierre Berthon, Bentley University

Colin Campbell, Kent State University

Ronika Chakrabarti, Lancaster University

Philip Grant, University of the Andes

Daniel Hall, KTH Royal Institute of

Technology, Stockholm

Stephen Humphrey, KTH Royal Institute of Technology, Stockholm
Neil Lilford, KTH Royal Institute of Technology, Stockholm

Adam Mills, Simon Fraser University Deon Nel, University of Pretoria

Kirk Plangger, King's College, London Leyland Pitt, Simon Fraser University Gerard Prendergast, Hong Kong Baptist University

Gavin Staude, Rhodes University

Nic Terblanche, University of

Stellenbosch

Karen Robson, Simon Fraser University Joseph Vella, University of Malta

Esmail Salehi Sangari KTH (Royal institute of Technology), Stockholm, Sweden. E-mail: ess@indek.kth.se 